\title{
A novel isoflavone, ME-344, targets the cytoskeleton in acute myeloid leukemia
}

\author{
Danny V. Jeyaraju ${ }^{1}$, Rose Hurren ${ }^{1}$, Xiaoming Wang ${ }^{1}$, Neil MacLean ${ }^{1}$, Marcela \\ Gronda $^{1}$, Aisha Shamas-Din ${ }^{1}$, Mark D. Minden ${ }^{1}$, Guri Giaever ${ }^{2}$, Aaron D. Schimmer ${ }^{1}$ \\ ${ }^{1}$ Princess Margaret Cancer Centre, University Health Network, Toronto, ON, Canada \\ ${ }^{2}$ Department of Pharmaceutical Sciences, University of British Columbia, Vancouver, BC, Canada
}

Correspondence to: Aaron D. Schimmer, email: aaron.schimmer@utoronto.ca

Keywords: tubulin, leukemia, synergy, mitochondria, reactive oxygen species

Received: October 19, 2015 Accepted: June 26, $2016 \quad$ Published: July 06, 2016

\section{ABSTRACT}

The isoflavone ME-344 is a potent anti-cancer agent with preclinical and clinical efficacy in solid tumors. Yet, the mechanism of action of ME-344 has not been fully defined and the preclinical efficacy in leukemia has not been established. Therefore, we investigated the anti-leukemic properties and mechanism of action of ME-344. In a panel of 7 leukemia cell lines, ME-344 was cytotoxic with an $\mathrm{IC}_{50}$ in the range of 70-260 $\mathrm{nM}$. In addition, ME-344 was cytotoxic to primary AML patient samples over normal hematopoietic cells. In an OCI-AML2 xenograft model, ME-344 reduced tumor growth by up to $95 \%$ of control without evidence of toxicity. Mechanistically, ME-344 increased mitochondrial ROS generation in leukemic cells. However, antioxidant treatment did not rescue cell death, suggesting that ME-344 had additional targets beyond the mitochondria. We demonstrated that ME-344 inhibited tubulin polymerization by interacting with tubulin near the colchicine-binding site. Furthermore, inhibition of tubulin polymerization was functionally important for ME-344 induced death. Finally, we showed that ME-344 synergizes with vinblastine in leukemia cells. Thus, our study demonstrates that ME-344 displays preclinical efficacy in leukemia through a mechanism at least partly related to targeting tubulin polymerization.

\section{INTRODUCTION}

Acute myeloid leukemia (AML) is the most common form of acute leukemia in adults, and its incidence increases with age [1]. Adults of more than 60 years of age have a less favorable prognosis than younger individuals due to toxicity and poor response rates of standard induction chemotherapy. In addition, relapsed and refractory AML is a highly aggressive and resistant disease with minimal response to chemotherapy $[1,2]$. Therefore, there is a need to develop new and improved therapies with low toxicity for the treatment of AML.

Isoflavone derivatives are potential novel therapies for the treatment of malignancies. Isoflavones are related to naturally occurring flavonoids, a class of secondary metabolites with phytoesterogen - plant-derived compounds with estrogenic properties. Some of the well-known isoflavones such as genistein, daidzein and phenoxodiol exhibit anti-cancer effects against various human cancers with high specificity [3-7]. Phenoxodial is the synthetic derivative of naturally occurring genistein that induces cell death in chemoresistant ovarian cancer cells through the mitochondrial apoptotic pathway via caspase- 2 mediated cleavage of Bid and proteasomal degradation of XIAP [6-8].

NV-128 is a second generation isoflavone derivative similar to phenoxodiol and induces caspase-independent cell death in epithelial ovarian cancer stem cells in part by targeting the mitochondria. NV-128 inhibits mTOR, causing mitochondrial depolarization and nuclear translocation of EndoG that kills cancer cells by cleaving nuclear DNA and condensing chromatin $[9,10]$. NV-128 also activates mitochondrial MAP/ERK kinase pathway and causes a loss of mitochondrial potential by upregulating Bax [9]. In addition, NV-128 facilitates the degradation of mitochondrial oxidative phosphorylation complex IV subunits Cox-I and Cox-IV by an unknown mechanism, and produces mitochondrial reactive oxygen species (ROS) leading to death of malignant cells $[9,10]$.

ME-344 is the active demethylated metabolite of NV128 that is more cytotoxic to cancer cells than NV-128 in 
preclinical studies $[9,10]$. While the specific cellular target of ME-344 is unknown, it induces cell death by interfering with mitochondrial oxidative phosphorylation by reducing the activity of complex I in HEK293T cells. This results in a reduction of mitochondrial oxygen consumption, a loss of mitochondrial membrane potential, and activation of the mitochondrial cell death signaling pathways [11]. In a recently reported phase I clinical trial in patients with refractory solid tumors, ME-344 was well tolerated and produced a partial clinical response in one patient and stabilized the disease in four others [12]. Currently, a phase $1 \mathrm{~b}$ clinical trial of ME-344 in combination with the topoisomerase inhibitor, topotecan, is underway in patients with solid small cell lung and ovarian cancers [13].

Despite the preclinical and clinical efficacy of ME-344 in solid tumors, its activity in leukemia has not been established. In addition, the cellular target of ME-344 is unknown and the mechanism of action has not been fully defined. In this study, we have investigated the preclinical efficacy of ME-344 in leukemia and defined a new mechanism of action targeting tubulin polymerization, which is distinct from vinca alkaloids.

\section{RESULTS}

\section{ME-344 is cytotoxic to leukemic cells in vitro}

To determine the potential of ME-344 in hematological malignancies, we evaluated the cytotoxicity of ME-344 against a panel of leukemic cell lines. Cells were treated with increasing concentrations of ME-344 to determine $\mathrm{IC}_{50}$ values. ME-344 reduced cell growth and viability of the tested cell lines with $\mathrm{IC}_{50}$ values in the range of 70-260 $\mathrm{nM}$ (Figure 1A and 1B). We confirmed these results using the SRB assay to measure growth and viability after ME-344 treatment in OCI-AML2, TEX and HL-60 cell lines (Supplementary Figure 1). To further establish the anti-leukemic potential of ME-344, we treated primary AML (gray lines) and normal hematopoietic (black lines) cells with increasing concentrations of ME-344. While ME-344 was toxic to AML patient samples with an $\mathrm{IC}_{50}$ of $630 \mathrm{nM}$ and $4 \mu \mathrm{M}$, normal hematopoietic cells remained viable in the concentrations tested (Figure 1C).

\section{ME-344 displays anti-tumor activity in a leukemia xenograft model}

To establish the anti-leukemic effects of ME-344 in vivo, we used a leukemia xenograft model and injected OCI-AML2 cells subcutaneously into SCID mice. Once tumors were palpable, mice were treated with intraperitoneal injections of ME-344 (50, 75, and $100 \mathrm{mg} / \mathrm{kg}$ ) or vehicle control every other day. Compared to vehicle control, ME-344 significantly reduced tumor growth $(* * P<0.001$ and $* * * P<0.0001$ ) (Figure $2 \mathrm{~A}$ and 2B) without any evidence of toxicity as measured by changes in weight (Figure 2C). In comparison between doses, a significant decrease in tumor weight was observed at $100 \mathrm{mg} / \mathrm{kg}$ compared to $50 \mathrm{mg} / \mathrm{kg}$ $\left({ }^{*} P<0.01\right)$. In addition, no changes in behavior as well as gross and histologic appearance of organs at necropsy were observed (Supplementary Figure 2). We reconfirmed these results by using another cell line MDAY-D2 (murine lymphosarcoma) in this leukemia xenograft model (Supplementary Figure 3). Thus, ME-344 displays pre-clinical efficacy against leukemia in vitro and in vivo.

\section{Mitochondrial ROS generated by ME-344 does not contribute to cell death}

It has been demonstrated that ME-344 induced death in solid tumor cells by increasing mitochondrial ROS levels and disrupting the mitochondria [9]. Therefore, we investigated mitochondrial ROS generation in leukemic cells after treatment with ME-344. Similar to the previous study, treatment of ME-344 increased mitochondrial ROS production in OCI-AML2 cells (Figure 3A). To test if mitochondrial ROS was responsible for ME-344induced cell death, we co-treated OCI-AML2 cells with ME-344 and N-acetylcysteine (NAC), an antioxidant that replenishes the GSH-GSSG system [14-17]. While co-treatment with NAC reduced levels of mitochondrial ROS (Figure 3A), it failed to rescue cell death induced by ME-344 in OCI-AML2 cells (Figure 3B). Thus, our results demonstrate that at least in leukemia cells, ME-344-mediated cell death is independent of mitochondrial ROS.

\section{ME-344 exerts anti-leukemic activity by targeting tubulin}

Treatment of cells with ME-344 induced changes in cellular morphology with perturbations in the shape of the plasma membrane. Similar changes in morphology were noted when treating cells with the tubulin inhibitor vinblastine (Supplementary Figure 4). Thus, we postulated that ME-344 might target the cytoskeleton.

We investigated the effects of ME-344 on actin and tubulin polymerization using in vitro assays. While, ME-344 did not have a notable effect on actin polymerization, treatment with the known actin dynamics inhibitor, cytochalasin $\mathrm{D}$, reduced the rate of actin polymerization (Figure 4A). On the other hand, ME-344 completely suppressed tubulin polymerization in the cell-free assay. As expected, taxol (paclitaxel), a known promoter of tubulin polymerization, enhanced tubulin polymerization, whereas vinblastine, a known inhibitor of tubulin polymerization, suppressed tubulin polymerization (Figure 4B). In OCI-AML2 cells, similar to colchicine, taxol, and vinblastine, ME-344 caused cell death with $\mathrm{IC}_{50}$ values in $\mathrm{nM}$ (Figure 4C). 

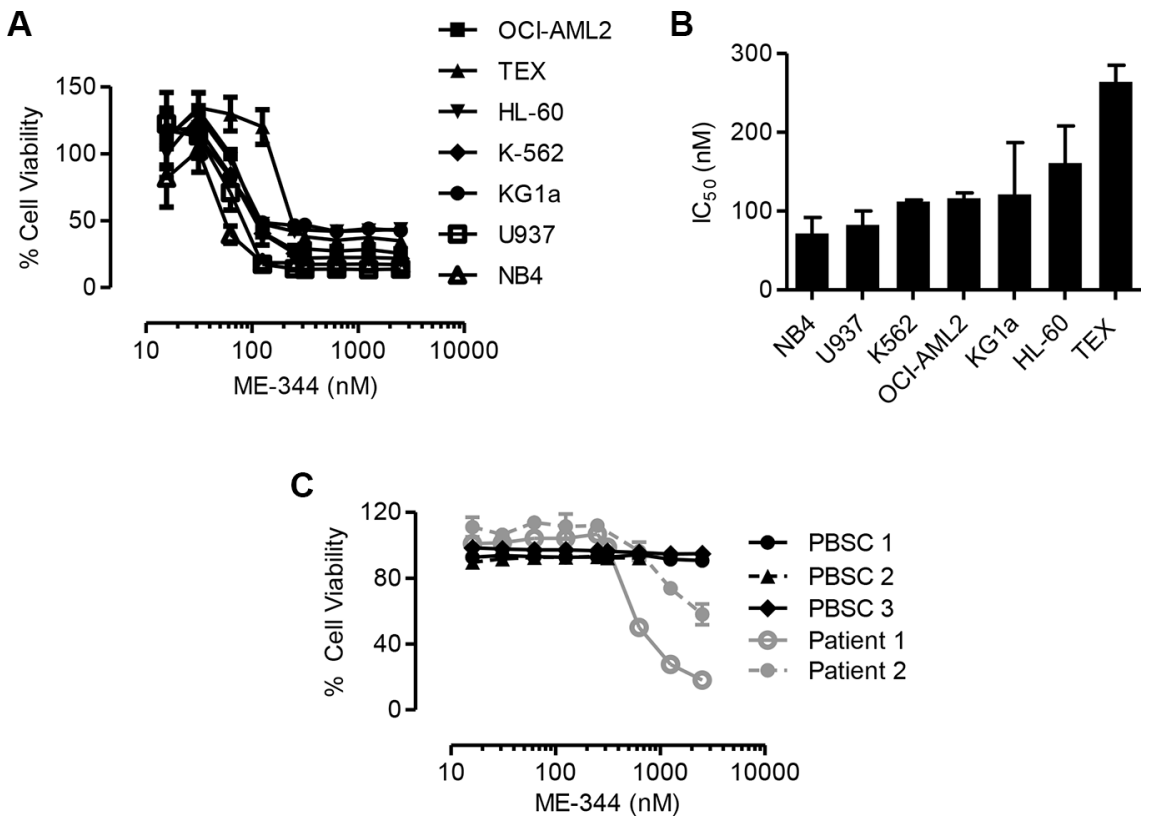

Figure 1: ME-344 is cytotoxic to leukemic cells in vitro. (A) Percentage of viable cells of indicated leukemic cell lines that were treated with increasing concentrations of ME-344. Cell viability was measured by MTS assay after 72 hours of treatment with ME-344. (B) $\mathrm{IC}_{50}$ values of ME-344 for the indicated leukemic cell lines tested from panel (A). (C) Normal hematopoietic samples (black) and primary patient samples (gray) were treated with increasing concentrations of ME-344. After 72 hours of treatment, cell viability was measured by Annexin V and PI staining followed by flow cytometry. Each line represents an independent donor. Data represent mean \pm SD of three independent experiments. The lines are connecting the data points. $\mathrm{IC}_{50}$ values were calculated using the Spline/LOWESS method in GraphPad Prism.
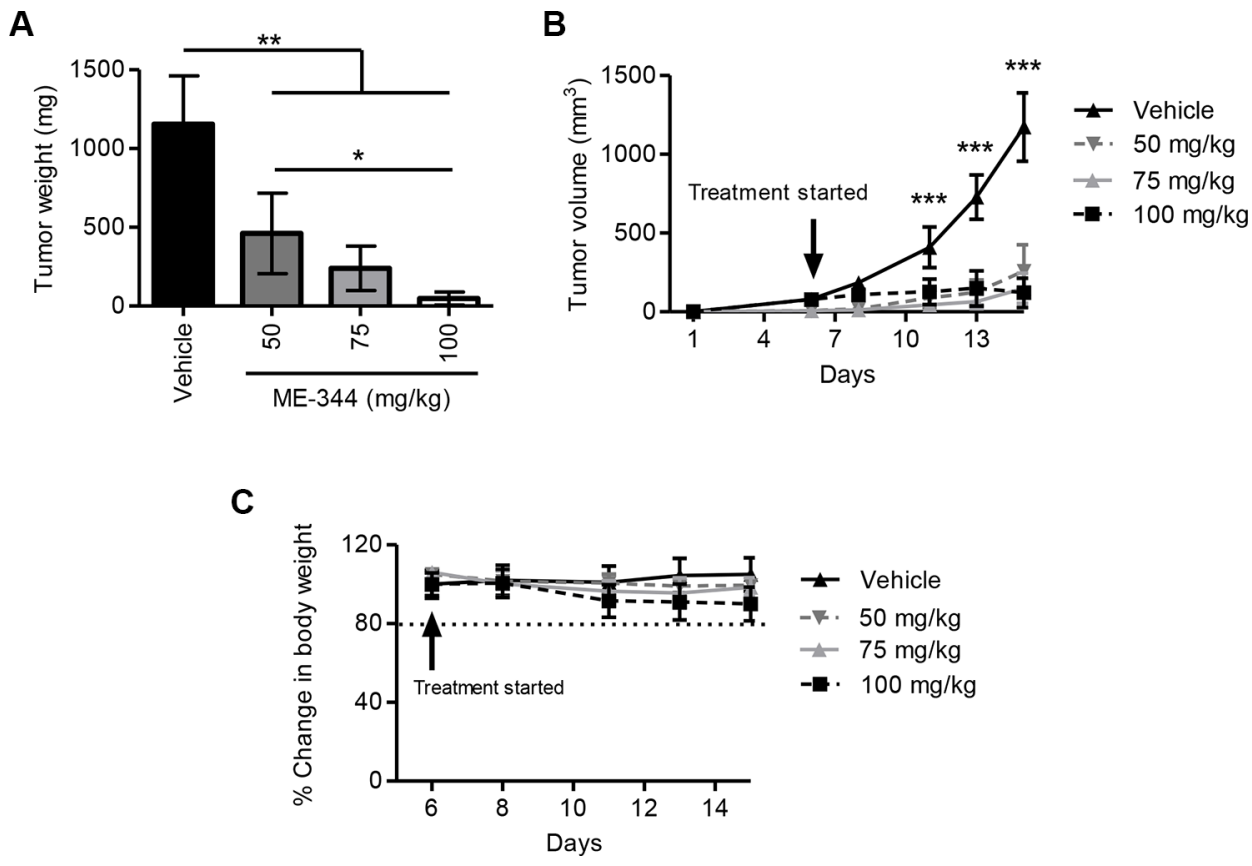

Figure 2: ME-344 displays antitumor activity in an in vivo xenograft mouse model. Tumor derived OCI-AML2 human leukemia cells $\left(1 \times 10^{6}\right)$ were injected subcutaneously into the flanks of male SCID mice. When tumors were palpable, animals were separated into four groups and were treated with ME-344 by i.p. injection (50, 75, and $100 \mathrm{mg} / \mathrm{kg}$ every other day) or vehicle control $(n=8$ per group). Tumor weight $(\mathbf{A})$, tumor volume $(\mathbf{B})$, and body weight $(\mathbf{C})$ were monitored over time. Mean $\pm \mathrm{SD}$; the lines are connecting the data points. ${ }^{*} P<0.01,{ }^{*} P<0.001$, and $* * * P<0.0001$ from a one-way ANOVA in panel (A) and a two-way ANOVA with Bonferroni posttests comparing all treatment groups in panel (B). 
To determine the interaction site of ME-344 with tubulin, we used a competitive colchicine-binding assay that is based on the fluorescent properties of the colchicinetubulin complex [18]. Our results show that ME-344 was able to compete with colchicine indicating that ME-344 targets tubulin by interacting at the colchicine binding site. This site is distinct from where vinblastine binds tubulin, since vinblastine did not compete with colchicine (Figure 4D). To further confirm that ME-344 targets tubulin polymerization, we treated cells with ME-344 and studied the impact on cell cycle. Similar to the effect of known tubulin inhibitors [19], ME-344 caused G2/M specific cell cycle arrest due to disrupting the microtubule assembly (Figure 4E).

\section{Tubulin resistant cell lines have decreased sensitivity to ME-344}

Having established that ME-344 targets tubulin in vitro, we investigated if inhibiting tubulin polymerization was functionally important for the toxicity of ME-344. We used the paired epidermoid carcinoma cell lines KB-3.1, with wild type tubulin, and KB-4.0-HTI36 a cell line resistant to tubulin inhibitors due to a single nucleotide substitution in $\alpha$-tubulin [20]. Consistent with our in vitro observations, KB-4.0-HTI36 cells had at least a 3-fold higher $\mathrm{IC}_{50}$ value and displayed resistance to ME-344 (Figure 4F) similar to their resistance to colchicine and vinblastine (Supplementary Figure 5). On the other hand, both cell lines had similar $\mathrm{IC}_{50}$ values for taxol that promotes tubulin polymerization (Supplementary Figure 5) which is consistent with the original observation by the group that developed these cell lines [20].

To further explore the effects of ME-344 on tubulin polymerization, we visualized the microtubule assembly using immunofluorescence in PPC-1 cells following treatment with colchicine and ME-344. We found that ME-344 causes morphological changes in the tubulin assembly (Supplementary Figure 6). Thus, inhibition of tubulin by ME-344 is functionally important for its cytotoxicity.

\section{ME-344 synergizes with vinblastine and is additive with AraC in leukemic cells}

Since tubulin inhibitors bind to many diverse sites on tubulin, the combination of two or more of these inhibitors can improve their efficacy [19]. Therefore,
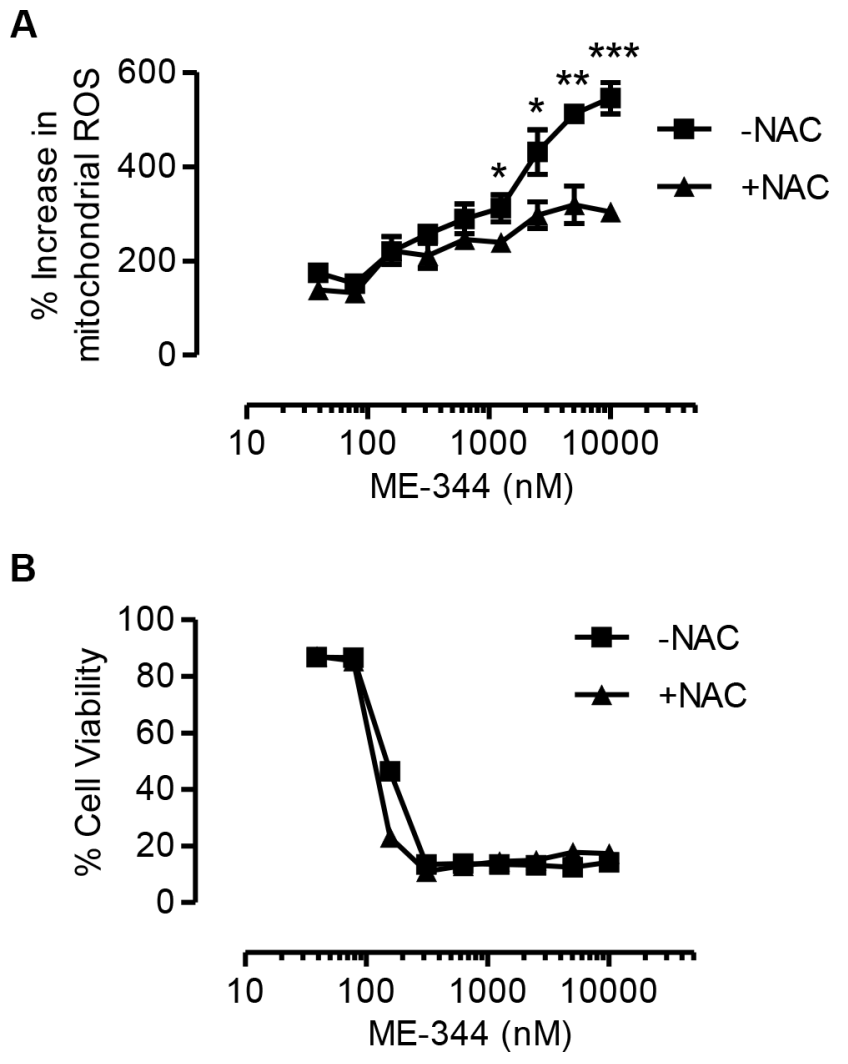

Figure 3: Antioxidant treatment does not rescue cell death induced by ME-344. OCI-AML2 cells were treated with increasing concentrations of ME-344 alone, and ME-344 with 5 mM NAC simultaneously for 72 hours. Accumulation of mitochondrial ROS was assessed by flow cytometry using Mitosox staining (A), and cell viability was measured by 7-AAD staining (B). Data represent mean \pm SD of three independent experiments. The lines are connecting the data points. ${ }^{*} P<0.05,{ }^{*} P<0.01$ and $* * * P<0.001$ from Student's $t$-test by comparing the means at a given concentration of ME-344. 
A

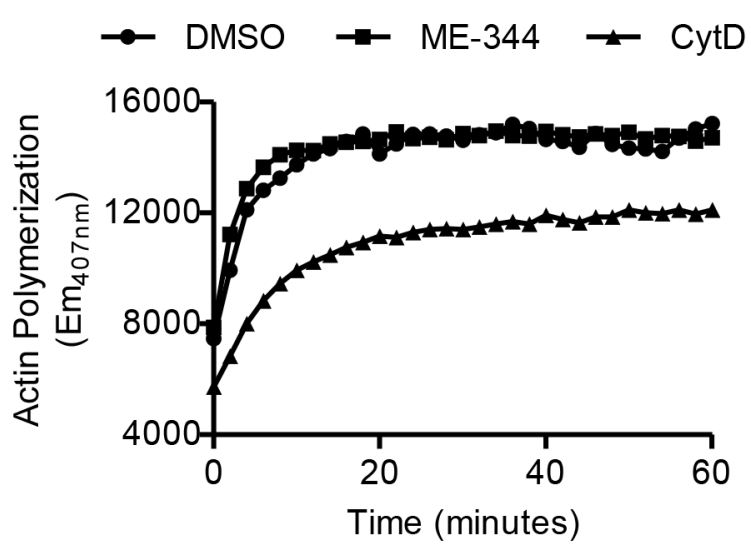

C

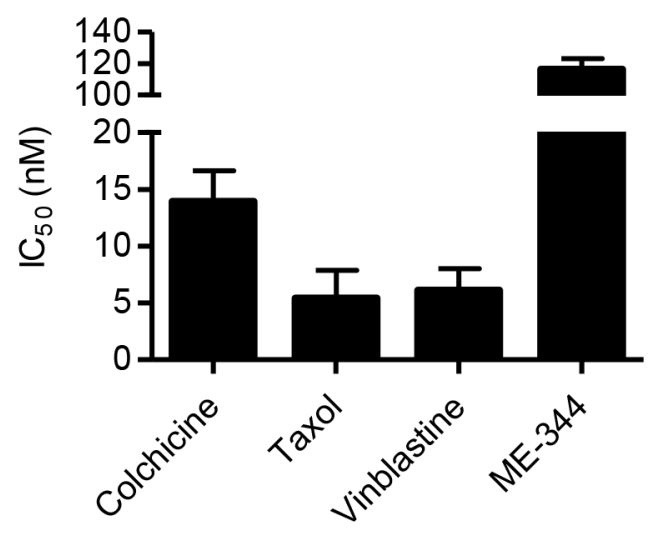

E

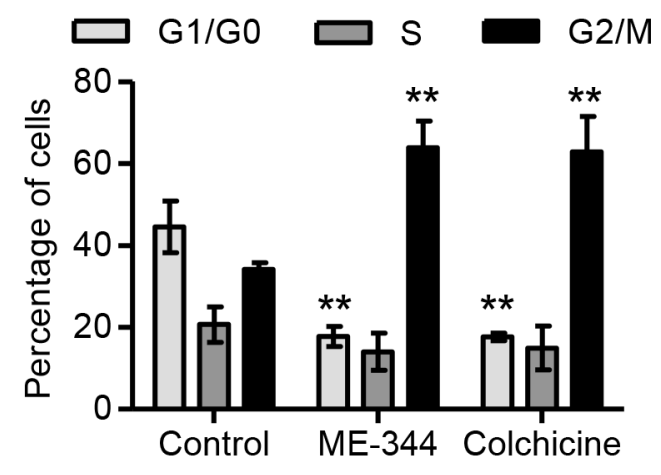

B

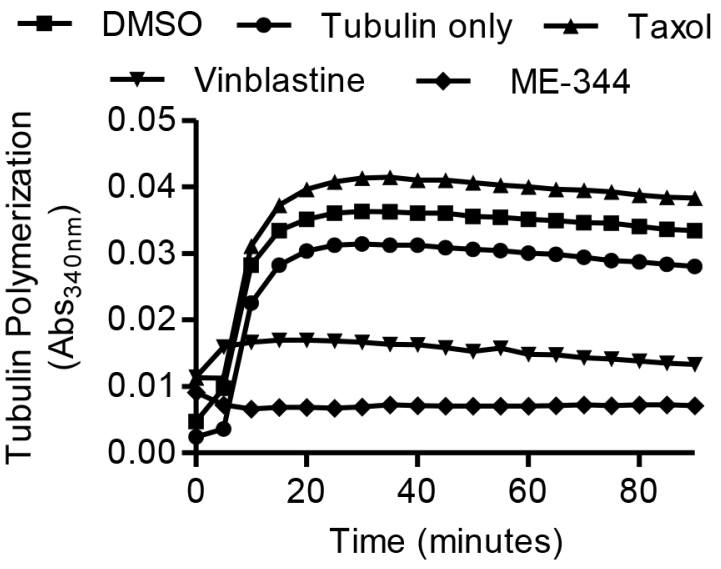

D

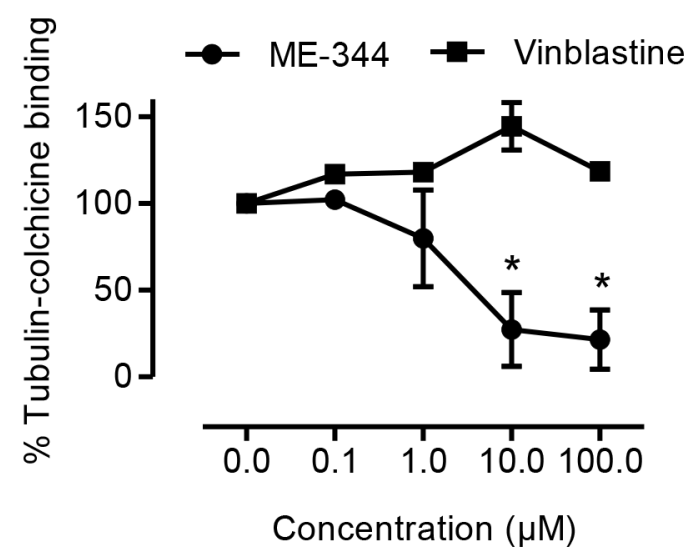

$\mathbf{F}$

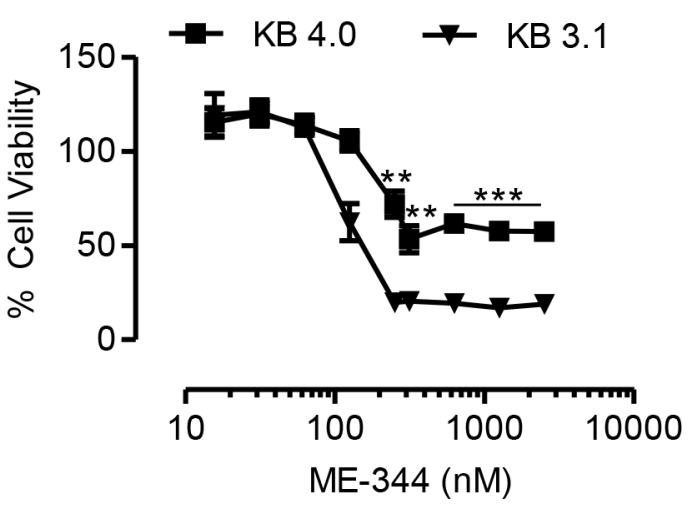

Figure 4: ME-344 targets the colchicine-binding site of tubulin in vitro. (A) Effect of $20 \mu \mathrm{M} \mathrm{ME}-344$ and $20 \mu \mathrm{M}$ cytochalasin D (CytD) on actin polymerization as measured by following the increase in fluorescence during conversion of pyrene G-actin (monomer) to pyrene F-actin. (B) Effect of $10 \mu \mathrm{M}$ ME-344, $10 \mu \mathrm{M}$ taxol, and $10 \mu \mathrm{M}$ vinblastine on tubulin polymerization, as measured by an increase in absorbance. (C) OCI-AML2 cells were treated with increasing concentrations of colchicine, taxol, vinblastine and ME-344. Cell viability was measured by MTS assay after 72 hours of treatment and $\mathrm{IC}_{50}$ values were calculated. (D) Percent tubulin-colchicine binding after incubating tubulin with increasing concentrations of ME-344 and vinblastine. (E) OCI-AML2 cells were treated with $100 \mathrm{nM}$ of ME-344 and colchicine to observe the impact on cell cycle. (F) KB-3.1 and KB-4.0-HTI36 cells were treated with increasing concentrations of ME-344. Cell viability was measured by MTS assay after 72 hours of treatment. Panels (A) and (B) show representative results, panels $(C)$ and $(F)$ show mean \pm SD of three independent experiments, and panels (D) and (E) show mean \pm SD of two independent experiments. ${ }^{*} P<0.05,{ }^{*} * P<0.01$ and $* * * P<0.001$ from Student's $t$-test by comparing the means at a given concentration in panels (D) and (F), and from two-way ANOVA in panel (E). 
to evaluate the extent of synergy of ME-344 with other tubulin inhibitors and anticancer drugs, we carried out treatments of different drug combinations in TEX and OCI-AML2 leukemia cell lines. Cells were treated with increasing concentrations of ME-344 along with increasing concentrations of vinblastine, cytarabine, daunorubicin, and the kinase inhibitors imatinib, sunitinib, and quizartinib. Cell growth and viability was measured 72 hours after incubation by MTS assay. Synergy, additivism, and antagonism were assessed using Excess Over Bliss Additivism [21, 22]. ME-344 showed strong synergy with vinblastine to reduce the growth and viability of TEX cells and showed moderate synergy in OCI-AML2 cells (Figure 5A-5D) $(* P<0.0001)$. In addition, ME-344 showed synergy with cytarabine to reduce the growth of both TEX and OCI-AML2 cells (Supplementary Figure 7). The combinations with the other agents were primarily additive or antagonistic at high drug concentrations (Supplementary Figures 8 and 9).

\section{A}

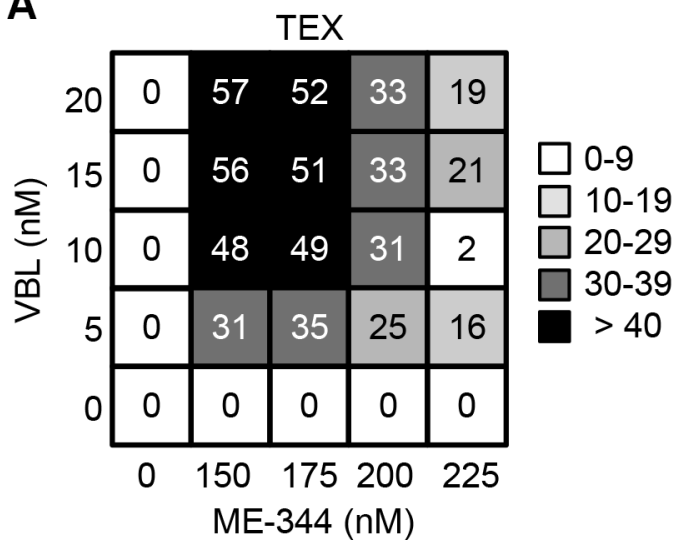

C

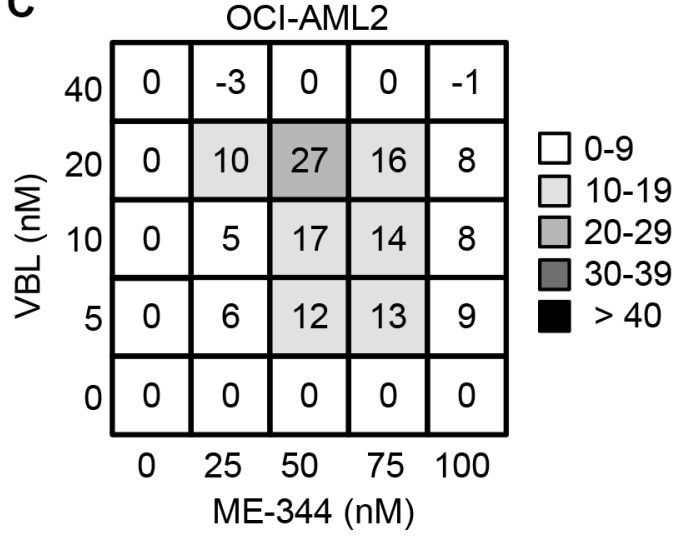

\section{DISCUSSION}

In this study, we demonstrated that ME-344 displays potent anti-leukemic activity using in vitro and in vivo methods. Thus, these data, along with the prior clinical efficacy of ME-344, support the clinical evaluation of ME-344 for patients with acute leukemia. In a previous phase I dose escalation clinical trial of ME-344 in patients with solid tumors, a maximal tolerated dose (MTD) of $10 \mathrm{mg} / \mathrm{kg}$ was established. Notably, in this clinical trial, a partial response for $\geq 52$ weeks was reported in one patient with small cell lung cancer, and four patients had prolonged stable disease [12].

To date, the mechanism of action and molecular targets of ME-344 have not been fully defined. Similar to previous studies, we demonstrated that ME-344 promoted mitochondrial ROS generation. However, increased mitochondrial ROS did not completely explain the mechanism of action of ME-344 in leukemia,
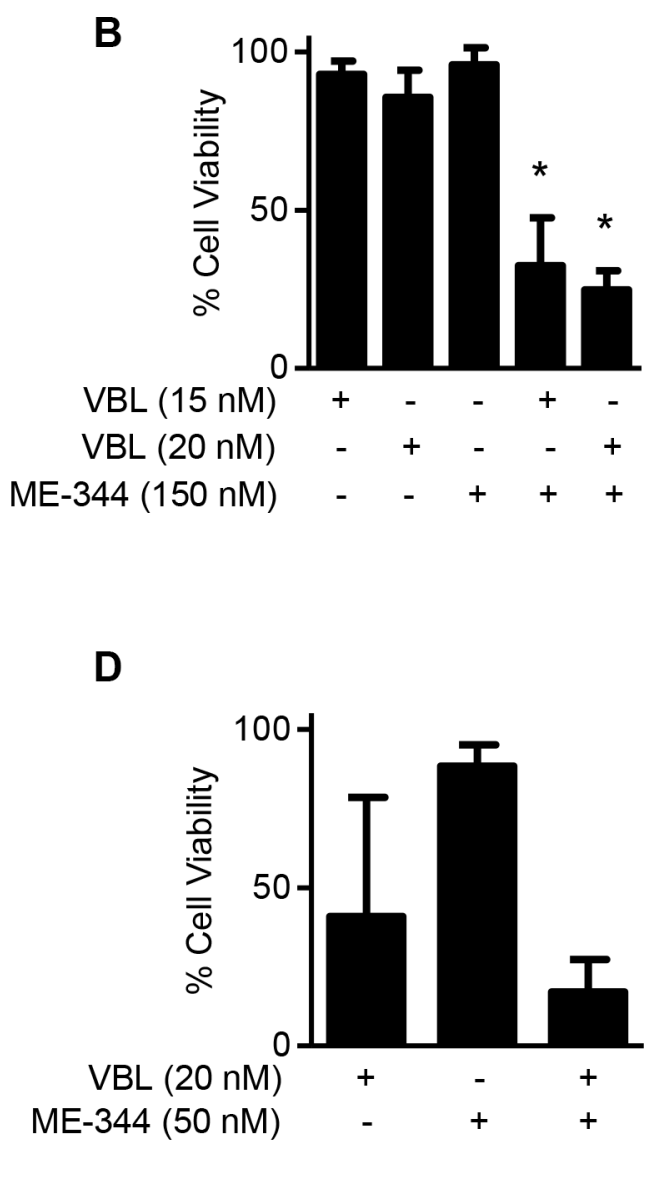

Figure 5: ME-344 synergizes with vinblastine in TEX cells and OCI-AML2 cells. (A and B) TEX and (C and D) OCI-AML2 cells were treated with the indicated concentrations of ME-344 and vinblastine (VBL) simultaneously. Cell viability was assessed using the MTS assay after 72 hours. Excess Over Bliss values above 10 were assigned as being synergistic. Representative synergistic combinations in TEX (B) and in OCI-AML2 (D) are shown. ${ }^{*} P<0.0001$ from one-way ANOVA. Data represent mean \pm SD of three independent experiments. 
suggesting that ME-344 may have other cellular targets. Therefore, we used in vitro assays to identify the cellular target of ME-344 in leukemia cells. We confirmed that ME-344 inhibited tubulin polymerization and interacted with tubulin at the colchicine binding site. This site is distinct from the binding site of vinca alkaloids. Thus microtubules appear to be at least one important molecular target for ME-344. In support of our results, another isoflavone glaziovianin A displayed a pattern of differential cytotoxicity in a panel of 39 cancer cell lines that suggested that it induced cell death by inhibiting tubulin polymerization [23]. In addition, it is noteworthy that neuropathy, which is a common toxicity of tubulin inhibitors, was a dose limiting toxicity in the phase I trial of ME-344 [12].

Further studies will be necessary to understand how inhibition of tubulin polymerization by ME-344 may be related to increased ROS generation. Potentially, these two findings could be linked through alterations in mitochondrial motility. By altering tubulin polymerization, ME-344 could impact mitochondrial motility leading to mitochondrial dysfunction. This possibility is supported by findings that 1-methyl-4-phenylpiridinium $(\mathrm{MPP}(+))$, the parkinsonian toxin, alters microtubule dynamics resulting in mitochondrial transport impairment and cell death [24].

In conclusion, ME-344 is a novel isoflavone based tubulin inhibitor that binds tubulin at a site distinct from vinca alkaloids. It has effective anti-leukemic properties in vivo and in vitro. Taken together with data from clinical trials in solid tumors, our study supports a clinical trial of ME-344 in patients with AML and other hematological malignancies.

\section{MATERIALS AND METHODS}

\section{Cell culture}

All leukemic cell lines were grown in IMDM media supplemented with $10 \%$ fetal bovine serum (FBS), $100 \mu \mathrm{g} / \mathrm{ml}$ penicillin and $100 \mathrm{U} / \mathrm{ml}$ streptomycin (all from Hyclone, Logan, UT). TEX cells were grown in the presence of $15 \% \mathrm{FBS}, 100 \mu \mathrm{g} / \mathrm{ml}$ penicillin, $100 \mathrm{U} / \mathrm{ml}$ streptomycin, $2 \mathrm{mM}$ L-glutamine, $20 \mathrm{ng} / \mathrm{ml}$ $\mathrm{SCF}$, and $2 \mathrm{ng} / \mathrm{ml} \mathrm{IL}-3$. The epidermoid carcinoma cell lines KB-3.1 and KB-4.0-HTI36 (a gift from Dr. F. Loganzo, Pearl River, NY) were grown in Dulbecco's Modified Eagle Medium (DMEM) supplemented with $10 \% \mathrm{FBS}$. All cells were incubated at $37^{\circ} \mathrm{C}$ in a humidified air atmosphere supplemented with $5 \% \mathrm{CO}_{2}$. Primary human AML samples were isolated from peripheral blood from consenting patients with AML, who had at least $80 \%$ malignant cells among low-density cells. AML cells were isolated by Ficoll density centrifugation. Except where otherwise noted, primary normal hematopoietic cells refer to normal mononuclear cells obtained from healthy consenting volunteers donating peripheral blood stem cells (PBSCs) for allogeneic stem cell transplantation after G-CSF mobilization. Primary cells were cultured at $37^{\circ} \mathrm{C}$ in IMDM, supplemented with $20 \%$ FBS, $100 \mu \mathrm{g} / \mathrm{ml}$ penicillin and $100 \mathrm{U} / \mathrm{ml}$ streptomycin. The University Health Network institutional review board approved the collection and use of human tissue for this study.

\section{Cell growth and viability assays}

The MTS assay was used for assessment of cell growth and viability as per the manufacturer's instructions (Promega, Madison, WI). Cell death was measured by Annexin V-fluoroscein isothiocyanate (FITC) and Propidium Iodide (PI) staining (Biovision Research Products, Mountain View, CA) or by 7-AAD staining (BD biosciences) using flow cytometry (FACS canto II, Becton Dickinson, FL) according to the manufacturer's instructions. Results were analyzed with FlowJo (TreeStar, Ashland, OR). $\mathrm{IC}_{50}$ values were calculated using the Spline/LOWESS method in GraphPad Prism.

\section{Tubulin polymerization and binding assays}

MAP-rich bovine tubulin (Cytoskeleton, Denver, $\mathrm{CO})$ was reconstituted in ice-cold polymerization buffer (80 mM PIPES pH 6.9, 0.5 mM EGTA, 2 mM MgCl , $10 \%$ glycerol and $1 \mathrm{mM} \mathrm{GTP)}$ at a concentration of $1.2 \mathrm{mg} / \mathrm{ml}$ and centrifuged at top speed for $5 \mathrm{~min}$ at $4^{\circ} \mathrm{C}$. Supernatant $(100 \mu \mathrm{l} /$ well) was added to ME-344 or the appropriate controls in a 96-well plate to obtain a final drug concentration of $10 \mu \mathrm{M}$. Absorbance was measured at $340 \mathrm{~nm}$ every $5 \mathrm{~min}$ for $90 \mathrm{~min}$ at $37^{\circ} \mathrm{C}$.

Competitive inhibition of colchicine binding to tubulin was performed using purified porcine tubulin (Cytoskeleton, Denver, CO) reconstituted at $0.5 \mathrm{mg} / \mathrm{ml}$ (80 mM PIPES pH 6.9, $0.5 \mathrm{mM}$ EGTA and $2 \mathrm{mM} \mathrm{MgCl}_{2}$ ). Briefly, the tubulin solution ( $300 \mu \mathrm{l} /$ sample) was incubated at $37^{\circ} \mathrm{C}$ for $60 \mathrm{~min}$ in the presence of compounds at varying concentrations and colchicine $(12 \mu \mathrm{M})$. Fluorescence of the colchicine-tubulin complex was measured in disposable cuvettes using excitation and emission wavelengths of $360 \mathrm{~nm}$ and $430 \mathrm{~nm}$, respectively.

\section{Actin polymerization assays}

Actin polymerization was measured using the actin polymerization Biochem kit (Cytoskeleton, Denver, CO). Briefly, $1 \mathrm{mg}$ of pyrene labeled muscle actin was resuspended with $50 \mu \mathrm{l}$ of ice cold sterile de-ionized water and was made up to a final concentration of $0.4 \mathrm{mg} / \mathrm{ml}$ using $5 \mathrm{mM}$ Tris- $\mathrm{HCl} \mathrm{pH} 8.0,0.2 \mathrm{mM} \mathrm{CaCl}_{2}$ and $200 \mathrm{mM}$ ATP. The assay was performed in a 96-well plate with the appropriate controls. The samples were excited at $365 \mathrm{~nm}$ and the emission was collected at $407 \mathrm{~nm}$. The plate was placed in the fluorimeter and samples were read once 
every $60 \mathrm{sec}$ for a total of $3 \mathrm{~min}$ to establish a baseline fluorescent measurement for all samples. After $3 \mathrm{~min}$, $20 \mu \mathrm{l}$ of ME-344 at a final concentration of $20 \mu \mathrm{M}$ was added and the plate was read for a further $20 \mathrm{~min}$ to test if ME-344 induces polymerization. After $20 \mathrm{~min}, 20 \mu \mathrm{l}$ of $10 \times$ Actin Polymerization Buffer was added and plate was read for 1 hour every $20 \mathrm{sec}$ or until the fluorescent signal plateaued.

\section{Cell cycle analysis}

OCI-AML2 cells were treated with $100 \mathrm{nM}$ of ME-344 or colchicine overnight, harvested, washed once in cold PBS and fixed overnight in cold $70 \%$ ethanol at $-20^{\circ} \mathrm{C}$. Cells were then pelleted, washed once with PBS and treated with $100 \mathrm{ng} / \mathrm{ml}$ DNase-free RNase A (Invitrogen, Carlsbad, CA) at $37^{\circ} \mathrm{C}$ for 30 minutes. Propidium Iodine $(5 \mu \mathrm{g} / \mathrm{ml})$ solution was added prior to measuring DNA content on a FACScalibur (Becton Dickinson, FL). Results were analyzed with FlowJo (TreeStar, Ashland, OR).

\section{Measurement of mitochondrial ROS}

Mitochondrial reactive oxygen species (ROS) was detected by staining cells with MitoSOX $(5 \mu \mathrm{M})$ and followed by flow cytometric analysis as described previously [25, 26]. Briefly, cells were stained with MitoSOX in HBSS buffer at $37^{\circ} \mathrm{C}$ for $30 \mathrm{~min}$, and then re-suspended in binding buffer with a viability dye (Annexin V or 7-AAD to identify viable cells and assess their reactive oxygen intermediate levels. Data were analyzed with FlowJo version 7.7.1 (TreeStar).

\section{Assessment of the anti-leukemia activity of ME-344 in mouse models of human leukemia}

OCI-AML-2 human leukemia cells $\left(1 \times 10^{6}\right)$ were injected subcutaneously into the flanks of male SCID mice (Ontario Cancer Institute, Toronto, ON). When the tumors were palpable, mice were treated with ME-344 by i.p. injection $(50,75$, or $100 \mathrm{mg} / \mathrm{kg}$ once every other day) over 11 days in saline or vehicle control ( $n=8$ per group). Caliper measurements were used to calculate tumor volumes $\left(\right.$ volume $=$ tumor length $\times$ width $\left.^{2} \times 0.5236\right)$ over time. At the end of the experiment, mice were sacrificed and the tumors excised and weighed.

\section{ACKNOWLEDGMENTS}

We thank Jill Flewelling for administrative assistance.

\section{CONFLICTS OF INTEREST}

All the authors have read and understood the journal's policy, and declare the following competing financial interests in relation to the study: MEI pharma provided funding for this work.

\section{FUNDING}

This work was supported by funds from MEI pharma and the Canadian Stem Cell Network. DVJ is a Fonds de recherche du Québec - Santé (FRQS) and Ontario Stem Cell Initiative (OSCI) postdoctoral scholar. ADS holds the Baker Chair in Leukemia and Related Diseases.

\section{REFERENCES}

1. Estey E, Dohner H. Acute myeloid leukaemia. Lancet. 2006; 368:1894-1907.

2. Siegel R, Naishadham D, Jemal A. Cancer statistics, CA Cancer J Clin. 2013; 63:11-30.

3. Adjakly M, Ngollo M, Boiteux JP, Bignon YJ, Guy L, Bernard-Gallon D. Genistein and daidzein: different molecular effects on prostate cancer. Anticancer Res. 2013; 33:39-44.

4. Peterson G, Barnes S. Genistein inhibits both estrogen and growth factor-stimulated proliferation of human breast cancer cells. Cell Growth Differ. 1996; 7:1345-1351.

5. Brown DM, Kelly GE, Husband AJ. Flavonoid compounds in maintenance of prostate health and prevention and treatment of cancer. Mol Biotechnol. 2005; 30:253-270.

6. Kamsteeg M, Rutherford T, Sapi E, Hanczaruk B, Shahabi S, Flick M, Brown D, Mor G. Phenoxodiol—an isoflavone analog -induces apoptosis in chemoresistant ovarian cancer cells. Oncogene. 2003; 22:2611-2620.

7. Silasi DA, Alvero AB, Rutherford TJ, Brown D, Mor G. Phenoxodiol: pharmacology and clinical experience in cancer monotherapy and in combination with chemotherapeutic drugs. Expert Opin Pharmacother. 2009; 10:1059-1067.

8. Sapi E, Alvero AB, Chen W, O’Malley D, Hao XY, Dwipoyono B, Garg M, Kamsteeg M, Rutherford T, Mor G. Resistance of ovarian carcinoma cells to docetaxel is XIAP dependent and reversible by phenoxodiol. Oncol Res. 2004; 14:567-578.

9. Alvero AB, Montagna MK, Holmberg JC, Craveiro V, Brown D, Mor G. Targeting the mitochondria activates two independent cell death pathways in ovarian cancer stem cells. Mol Cancer Ther. 2011; 10:1385-1393.

10. Alvero AB, Montagna MK, Chen R, Kim KH, Kyungjin K, Visintin I, Fu HH, Brown D, Mor G. NV-128, a novel isoflavone derivative, induces caspase-independent cell death through the Akt/mammalian target of rapamycin pathway. Cancer. 2009; 115:3204-3216.

11. Lim SC, Carey KT, McKenzie M. Anti-cancer analogues ME-143 and ME-344 exert toxicity by directly inhibiting mitochondrial NADH: ubiquinone oxidoreductase (Complex I). Am J Cancer Res. 2015; 5:689-701. 
12. Bendell JC, Patel MR, Infante JR, Kurkjian CD, Jones SF, Pant S, Burris HA, 3rd, Moreno O, Esquibel V, Levin W, Moore KN. Phase 1, open-label, dose escalation, safety, and pharmacokinetics study of ME-344 as a single agent in patients with refractory solid tumors. Cancer. 2015; 121:1056-1063.

13. Mei Pharma I, Scri Development Innovations LLC. ME-344 Given in Combination With Hycamtin ${ }^{\circledR}$ in Patients With Solid Tumors 2015.

14. Ribas V, Garcia-Ruiz C, Fernandez-Checa JC. Glutathione and mitochondria. Front Pharmacol. 2014; 5:151.

15. Wright DJ, Renoir T, Smith ZM, Frazier AE, Francis PS, Thorburn DR, McGee SL, Hannan AJ, Gray LJ. $\mathrm{N}$-Acetylcysteine improves mitochondrial function and ameliorates behavioral deficits in the R6/1 mouse model of Huntington's disease. Transl Psychiatry. 2015; 5:e492.

16. Mari M, Morales A, Colell A, Garcia-Ruiz C, FernandezCheca JC. Mitochondrial glutathione, a key survival antioxidant. Antioxid Redox Signal. 2009; 11:2685-2700.

17. Mari M, Morales A, Colell A, Garcia-Ruiz C, Kaplowitz N, Fernandez-Checa JC. Mitochondrial glutathione: features, regulation and role in disease. Biochim Biophys Acta. 2013; 1830:3317-3328.

18. Bhattacharyya B, Wolff J. Promotion of fluorescence upon binding of colchicine to tubulin. Proc Natl Acad Sci USA. 1974; 71:2627-2631.

19. Jordan MA, Wilson L. Microtubules as a target for anticancer drugs. Nat Rev Cancer. 2004; 4:253-265.

20. Loganzo F, Hari M, Annable T, Tan X, Morilla DB, Musto S, Zask A, Kaplan J, Minnick AA, Jr., May MK, Ayral-Kaloustian S, Poruchynsky MS, et al. Cells resistant to HTI-286 do not overexpress P-glycoprotein but have reduced drug accumulation and a point mutation in alphatubulin. Mol Cancer Ther. 2004; 3:1319-1327.

21. Goswami CP, Cheng L, Alexander PS, Singal A, Li L. A New Drug Combinatory Effect Prediction Algorithm on the Cancer Cell Based on Gene Expression and Dose-Response Curve. CPT Pharmacometrics Syst Pharmacol. 2015; 4:e9.

22. Borisy AA, Elliott PJ, Hurst NW, Lee MS, Lehar J, Price ER, Serbedzija G, Zimmermann GR, Foley MA, Stockwell BR, Keith CT. Systematic discovery of multicomponent therapeutics. Proc Natl Acad Sci USA. 2003; 100:7977-7982.

23. Yokosuka A, Haraguchi M, Usui T, Kazami S, Osada H, Yamori T, Mimaki Y. Glaziovianin A, a new isoflavone, from the leaves of Ateleia glazioviana and its cytotoxic activity against human cancer cells. Bioorg Med Chem Lett. 2007; 17:3091-3094.

24. Cartelli D, Ronchi C, Maggioni MG, Rodighiero S, Giavini E, Cappelletti G. Microtubule dysfunction precedes transport impairment and mitochondria damage in MPP+ -induced neurodegeneration. J Neurochem. 2010; 115:247-258.

25. Skrtic M, Sriskanthadevan S, Jhas B, Gebbia M, Wang X, Wang Z, Hurren R, Jitkova Y, Gronda M, Maclean N, Lai CK, Eberhard Y, Bartoszko J, et al. Inhibition of mitochondrial translation as a therapeutic strategy for human acute myeloid leukemia. Cancer Cell. 2011; 20:674-688.

26. Sriskanthadevan S, Jeyaraju DV, Chung TE, Prabha S, Xu W, Skrtic M, Jhas B, Hurren R, Gronda M, Wang X, Jitkova Y, Sukhai MA, Lin FH, et al. AML cells have low spare reserve capacity in their respiratory chain that renders them susceptible to oxidative metabolic stress. Blood. 2015; $125: 2120-2130$. 